\title{
Teaching Medical Students and Residents about Homelessness: Complex, Evidence-Based, and Imperative
}

\author{
Adam M. Brenner ${ }^{1} \cdot$ Anthony P. S. Guerrero $^{2} \cdot$ Eugene V. Beresin $^{3}$. \\ John H. Coverdale ${ }^{4}$ - Richard Balon ${ }^{5}$ - Alan K. Louie ${ }^{6}$ - Laura Weiss Roberts ${ }^{6}$
}

Received: 29 April 2016 / Accepted: 4 May 2016/Published online: 24 May 2016

(C) Academic Psychiatry 2016

Home is where the heart is.

-Pliney the Elder

Be it ever so humble, there's no place like home.

- John Howard Payne

Our traditions are replete with proverbs addressing the concept of home. Robert Frost famously wrote, "Home is the place where, when you have to go there, they have to take you in." The staying power of this and other aphorisms reflect the centrality of the concept of home for our deepest sense of ourselves - our aspirations toward safety, dignity, and love. In light of this, it is perhaps not surprising that there would be a strong relationship between homelessness, mental health, and mental illness. Affecting people of all ages, genders, races, ethnicities, and health statuses, homelessness is a significant public health problem in the USA and throughout the world. Especially in cities with high and rising per capita rates of homelessness, it may be the norm rather than the exception to have a significant proportion of patients on a hospital

Adam M. Brenner

Adam.Brenner@UTSouthwestern.edu

University of Texas Southwestern Medical Center, Dallas, TX, USA

2 University of Hawai'i John A. Burns School of Medicine, Honolulu, HI, USA

3 Harvard Medical School, Boston, MA, USA

4 Baylor College of Medicine, Houston, TX, USA

5 Wayne State University, Detroit, MI, USA

6 Stanford University, Stanford, CA, USA teaching service be homeless or inadequately sheltered. Psychiatry educators are then faced with the challenge of teaching students how to best understand and respond to the medical and psychiatric presentations of people who are homeless.

The Department of Housing and Urban Development's Annual Homelessness Assessment Report to Congress provides a snapshot of homelessness each year on a single night in January [1]. The most recent count in 2015 found 564,708 total homeless people, both sheltered and unsheltered. This included 127,787 children at that single point in time. The number of people who are homeless over time is of course significantly higher; the National Center for Family Homelessness (using a broader definition of homelessness that includes children living in motels or trailer parks or doubled up with relatives) estimates that 2.5 million children are homeless at some point each year [2].

Homeless patients constitute a bio-psycho-socially vulnerable and clinically challenging special population. Major social causes and correlates of homelessness include poverty, lack of affordable housing, lack of educational attainment, and unemployment [3]. Psychological contributors to homelessness include trauma and domestic violence when victims without other resources leave their homes for what they perceive to be the relative safety of the streets. Serious mental illness and addictions are also risk factors for homelessness [4]. Psychotic illnesses, for example, can interfere with the capacity to remain employed and contribute to a downward path into extreme poverty, while also fraying or severing ties to family and friends that could otherwise mitigate and prevent the descent into homelessness.

Homelessness itself is a stress that increases the risk of depression, anxiety, substance use disorders, suicidal 
ideation, and trauma [5]. Homeless persons are commonly assaulted physically or sexually, robbed, incarcerated for trespassing, and at risk of becoming sexually exploited or trafficked. In fact, the rates of victimization (physical assault, sexual assault, robbery, etc.) among homeless persons have been judged to be between 73 and $87 \%$ for lifetime rates and as high as $45 \%$ for monthly rates [6]. The stressors associated with homelessness can trigger mental illness and profoundly exacerbate preexisting conditions, compounding problems created by a lack of available resources and limitations in access to care. Street health studies have also demonstrated profound medical comorbidities in homeless persons that additionally complicate their mental health issues [7, 8]. Furthermore, homeless families with children face substantial challenges to the social, economic, and educational development of the children [9].

One qualitative study of formerly homeless persons with serious mental illness illustrated the complex interplay of cause and effect [10]. The study subjects reported numerous premature deaths in their families of origin, often occurring in the context of the accumulation of chronic stress through poverty, poor health, and social exclusion. A prominent recurrent theme was the snowballing of adversity - childhood losses, abandonments, and abuse, followed by problems with substance use and difficulties in school during adolescence, further followed by severe psychiatric symptoms, legal problems, incarceration, medical illnesses, and chronic poverty as adults. Childhood trauma and loss increase the risk of later homelessness, especially among young adults [11]. In particular, experiences of separation from parents or experiences of being displaced from home (running away, being put in foster care) were strongly associated with future homelessness. The same authors also noted that mental disorders and substance abuse can follow homelessness in young people with "bidirectional processes underlying the link between drug use and homelessness such that the presence of one may predispose an individual to the other" ([11] p. 470). Similarly, effective substance abuse treatment may assist in reducing homelessness [12] and providing housing for those homeless with major mental disorders may benefit their cognitive functioning [13].

Addressing the interplay between homelessness and mental disorders can inform curricula and teaching practices about prevention and advocacy programs. Educators may find it especially useful to distinguish between being housed and having a home. Qualitative research has been useful in unpacking the multiple meanings of home. Padgett et al. use the term ontological security to capture the subjective "feeling of well-being that arises from a sense of constancy in one's social and material environment which, in turn, provides a secure platform for identity development and self-actualization" ([14], p. 1926). It is entirely possible to have a roof over one's head - to have found housing - without having a functional sense of home. The recently homeless men and women interviewed emphasized that essential elements of feeling at home included control of one's space and a freedom from supervision, privacy and freedom from surveillance, safety and freedom from vigilance, and a secure base for rebuilding one's social identity and roles.

The experience of homelessness represents a complex psychological condition that involves multiple stresses and deprivations. In addition, as noted above, the status of being both mentally ill and homeless is certainly a physically dangerous state, and simply being sheltered does not provide the sense of safe harbor and refuge that is part of being in one's own home. Notably, the ability to control at least some elements of a living situation and to have a degree of choice among the options for housing and services leads to better outcomes for supportive housing programs, including greater residential stability and reductions in psychiatric symptoms [15]. The research underlines the essential messages of our proverbs and aphorisms: home is a place where a person feels safety and dignity, secure enough to strengthen ties of love and to repair the many possible wounds to the self and identity.

There is great value in providing opportunities for exposing students and residents to the psychiatric presentations of homeless persons and their unique mental health needs. Owusu et al. [16] described a program in which medical students screened patients at a homeless shelter and educated the staff about mental illness. Their screening found that $68 \%$ of those staying at the shelter were positive for a psychiatric diagnosis, most commonly depression, anxiety, and posttraumatic stress disorder. In addition to assisting residents and staff, the students in this program learned about the barriers to care for the homeless population and what kinds of leadership skills were necessary to address them. Morrison et al. [17] reported that experiences with homeless patients in the context of the psychiatry clerkship can result in an increase in positive attitudes of medical students toward this population, possibly related to the implicit attitudes of the faculty and residents they worked with. Recently, Fleisch et al. [18] reported on a street psychiatry rotation for residents, which focused on learning to engage homeless people on the street in order to connect them with case management. Student-run clinics also provide opportunities for medical students in particular to learn about the homeless population [19], and mobile crisis services may also provide a rich team-based milieu that can demonstrate effective outreach [20].

In this issue, Stovall et al. [21] describe the ethical tensions involved in the care of homeless patients and the dilemmas that arose for educators in how to teach their students and residents about these issues. The 
conditions of homelessness, which involve a profound disruption of the typical boundaries of private life, necessarily challenge clinicians to stretch their conceptualization of the usual boundaries of the role and interventions of psychiatry. The authors note that working with homeless patients "raises questions not usually encountered in a clinic about confidentiality, [clinician] personal safety, and a patient's autonomy" [21]. This work provides a valuable contribution to our literature in defining the educational challenge and providing both a conceptual framework and specific tips for equipping trainees to tackle these ethical issues.

Working with patients who are homeless provides learners with an excellent opportunity to link the psycho-social with biological problems in developing comprehensive case formulations and developing management plans. However, the complexity of the multiple stressors and needs of homeless individuals has the potential to overwhelm medical students and residents. The harsh social realities and lack of resources experienced by homeless individuals can evoke a sense of frustration, helplessness, foreboding, and even anger about the lack of social justice. Trainees may also feel frustrated when faced with homeless patients who reject their offers of care and housing, perhaps stemming from distrust learned through repeated victimization or psychiatric symptomatology. These experiences can test the limits of one's identity as a physician and healer and can exhaust one's wellspring of compassion, leading to the adoption of self-protective attitudes and behaviors (e.g., distancing from patients psychologically or dedicating less time to the care of homeless patients) [22]. As with other difficult patients, educators should incorporate supervisory systems to monitor and to rapidly respond to student reactions that might distort clinical judgment and care $[17,23]$. The professional virtue of self-effacement is critical to this work [24]. Self-effacement is the intentional setting aside of the clinician's personal reactions and values. This practice enables learners and clinical teachers to decrease the risk that the physician-patient relationship will be compromised by reflexive discriminatory reactions to patient attributes such as poverty, lack of education, or poor hygiene.

Psychiatry educators can also address the challenges facing patients who are homeless in additional ways. Curricula might include instruction on advocacy and provide hands-on opportunities to press for local and regional changes in policy and health care delivery. Baribeau and colleagues [25] integrated homeless health into a family medicine clerkship. They demonstrated that a mandatory clinical experience in homeless health can meaningfully contribute to a comprehensive advocacy curriculum. Similar experience could potentially be adapted and included in psychiatry clerkships. David Satcher [26], the former US Surgeon General, has called for a public health approach to mental health that advocates seeing the entire community as the psychiatrist's potential patient and addressing root socioeconomic factors. Training programs that take up this challenge might include teaching social prescribing, that is, the process of actively suggesting and guiding patients to social services, advocacy organizations, and other resources. Such education could very effectively help psychiatry residents who otherwise may not have exposure to the same degrees of poverty or displacement that trainees in other countries may have to achieve various milestone competencies, including in resource management, community-based care, the demonstration of compassion, and the demonstration of sensitivity to diversity.

A recent special collection in Academic Psychiatry [27] highlighted the many opportunities at the interface of psychiatry training and veterans' mental health. Hospitals within the Veterans Health Administration may be a particularly useful venue to introduce trainees to effective and evidence-informed programs to decrease homelessness and improve the health outcomes of homeless individuals. The Department of Veterans Affairs (VA) has been pursuing an ambitious agenda of ending veteran homelessness with considerable success (e.g., decreased rates of psychiatric symptoms, decreased rates of suicide and accidental death, increased rates of sustained housing) and demonstrated "what is possible within an integrated care system to truly be a safety net for those most vulnerable and disconnected" ([28], p. S185). Engagement with such programs is enriching educationally, but it also may reduce the risk of demoralization and even secondary trauma experienced by clinicians-in-training who work with this multi-problem patient population. Several of us (RB, AB, LWR) have resident rotations that include VA homeless outreach and domiciles and succeed in introducing residents to the challenges and the innovative solutions available for this important population.

Finally, attention to the subjective meaning of being homeless for the individual patient can teach students and residents to craft multidisciplinary treatment plans that are patient-centered and embrace the patient's aspirations not only to be housed, but also to secure a base from which they can reclaim roles as providers, parents, and supports for others. The impact of home on family life, and on single parents in particular, should be an additional part of the curriculum, as it has profound implications for attachment and the achievement of social, cognitive, and social-emotional developmental milestones in youth. Explication of the interplay between homelessness and mental and physical illnesses, 
trauma, and substance use can assist trainees in appreciating the complexity of the branching web of social deprivation, socioeconomic disadvantage, and the presentation of psychiatric illness.

\section{Compliance with Ethical Standards}

Disclosures On behalf of all authors, the corresponding author states that there is no conflict of interest.

\section{References}

1. Henry M, Shivji A, De Sousa T, et al. Annual Homelessness Assessment Report (AHAR) to congress, part 1: point-in-time estimates of homelessness. 2015. Available at http://works.bepress. com/dennis culhane/192/. Accessed 25 April 2016.

2. The National Center on Family Homelessness. America's youngest outcasts: a report card on child homelessness. American Institutes for Research. 2013. Available at http://www.air.org/resource/ americas-youngest-outcasts-report-card-child-homelessness. Accessed 25 April 2016.

3. Mago VK, Morden HK, Fritz C, et al. Analyzing the impact of social factors on homelessness: a Fuzzy Cognitive Map approach. BMC Med Inform Decis Mak. 2013;13:94.

4. Suglia SF, Chambers E, Sandel M. Poor housing quality and housing instability. In: Compton MR, Shim RS, editors. The social determinants of mental health. Arlington: American Psychiatric Association Publishing; 2015. p. 1-22.

5. Munoz M, Crespo M, Perez-Santos E. Homelessness effects on men's and women's health. Int J Ment Health. 2005;34:47-61.

6. Roy L, Crocker AG, Nicholls TL, et al. Criminal behavior and victimization among homeless individuals with severe mental illness: a systematic review. Psychiatr Serv. 2004;65:739-50.

7. Brett T, Arnold-Reed DE, Troeung L, et al. Multimorbidity in a marginalized, street-health Australian population: a retrospective cohort study. BMJ Open. 2014;4:1-8.

8. Tinnemann P, Bauer TE, Castro JD, et al. Street health: crosssectional study identifying social medicine issues amongst patients of the Health Center for Homeless in Berlin, Germany. Soc Med. 2014;8:23-30.

9. Beresin G, Scholzman S, Coleman M, Schoen L. The plight of homeless children in the United States. The clay center for young health minds. 2015. Available at http://www.mghclaycenter.org/ parenting-concerns/infants-toddlers/plight-homeless-childrenunited-states/. Accessed 25 April 2016.

10. Padgett DK, Smith BT, Henwood BF, Tiderington E. Life course adversity in the lives of formerly homeless persons with serious mental illness: context and meaning. Am J Orthop. 2012;82:42130 .
11. Shelton KH, Taylor PJ, Bonner A, Van den Bree M. Risk factors for homelessness: evidence from a population based study. Psychiatr Serv. 2009;60:465-72.

12. Goldfinger SM, Schutt RK, Tolomiczenko GS, et al. Housing placement and subsequent days homeless among formerly homeless adults with mental illness. Psychiatr Serv. 1999;50:674-9.

13. Seidman LJ, Schutt RK, Caplan B, et al. The effect of housing interventions on neuropsychological functioning among homeless persons with mental illness. Psychiatr Serv. 2003;54:905-8.

14. Padgett DK. There's no place like (a) home: ontological security among persons with serious mental illness in the United States. Soc Sci Med. 2007;64:1925-36.

15. Nelson G. Housing for people with serious mental illness: approaches, evidence, and transformative change. J Sociol Soc Welf. 2010;37(4):123-46.

16. Owusu Y, Kunik M, Coverdale J, et al. Lessons learned: a "homeless shelter intervention" by a medical student. Acad Psychiatry. 2012;36:219-22.

17. Morrison A, Roman B, Borges N. Psychiatry and emergency medicine: medical student and physician attitudes toward homeless persons. Acad Psychiatry. 2012;36:211-4.

18. Fleisch SB, Kelly AC. Street psychiatry as a community rotation for residents: the UNC homeless support program. Acad Psychiatry. 2014;38:246-7.

19. Batra P, Chertok JS, Fisher CE, Manseau MW, Manuelli VN, Spears J. The Columbia-Harlem homeless medical partnership: a new model for learning in the service of those in medical need. $\mathrm{J}$ Urban Health. 2009;86(5):781-90.

20. Guo S, Biegel DE, Johnsen JA, Dyches H. Assessing the impact of community based mobile crisis services on preventing hospitalization. Psychiatr Serv. 2001;52:223-8.

21. Stovall J, Fleisch SB, McQuistion HL, Hackman A, Harris T. Ethics and the treatment of the mentally ill, homeless person: a perspective on psychiatry resident training. Acad Psychiatry. 2015. doi:10. 1007/s40596-015-0330-0.

22. Coverdale J, McCullough LB. Responsibly managing student's learning experiences in student-run clinics: a virtues-based ethical framework. Teach Learn Med. 2014;26:312-5.

23. Roberts LW. Difficult patients. In: Roberts LW, editor. A clinical guide to psychiatric ethics. Arlington: American Psychiatric Association Publishing; 2016. p. 167-77.

24. Coverdale J, McCullough LB, Roberts LW. The ethics of psychiatric education. Psychiatr Clin N Am. 2009;32:413-21.

25. Baribeau D, Ramji N, Slater M, Weyman K. An advocacy experience for medical students. Clin Teach. 2016;13:1-5.

26. Satcher D, Shim RS. A call to action: addressing the social determinants of mental health. In: Compton MT, Shim RS, editors. The social determinants of mental health. Arlington: American Psychiatric Association Publishing; 2015. p. 1-22.

27. Warner $\mathrm{CH}$. A decade of war: adapting to meet the mental health training demands. Acad Psychiatry. 2015;39:351-3.

28. O'Toole T, Pape L, Kane V. Ending homelessness - then what. Am J Public Health. 2013;Supplement 2:185-7. 